\title{
Perbandingan Pengaruh Beberapa Jenis Pupuk Mengandung Fosfat terhadap Kehilangan Hara Melalui Pelindian pada Tanah Gambut
}

\author{
Comparison Effect of Several Phosphate Contain Fertilizers to Nutrient Loss Trough \\ Leaching on Peat Soil \\ IGM. Subiksa ${ }^{1 *)}$ \\ ${ }^{1}$ Indonesian Soil Research Institute \\ Kampus Penelitian Pertanian Cimanggu Bogor, Kota Bogor, Jawa Barat 16114 \\ ${ }^{*}$ Penulis untuk korespondensi: igm_subiksa@yahoo.co.id
}

\begin{abstract}
Peat soil have specific nutrient adsorption characteristics which are affected by soil $\mathrm{pH}$ dependent charge. Therefore, nutrient management on such soil should be done using different approach compared to mineral soil. Research on the comparison effects of several types of phosphate containing fertilizers to nutrient loss through leaching on peat soil has been carried out in greenhouse using coulom experiments. The objectives of this study was to evaluate the rate of primary macro nutrient loss and look for fertilization technology which can reduced leaching rate. The study used a randomized block design of 14 treatments with 3 replications. The treatments were complete control treatment, partial control and 4 types of P contain fertilizer, namely SP-36, NPK compound, Chrismast Island Phosphate Rock (CIRP), and Pugam each of them with 3 levels dose. The peat soil used was ombrogenous peat with hemic maturity level taken from OKI Regency, South Sumatra. Watering is done every 2 days with $350 \mathrm{ml}$ ion-free water/pot. The results showed that $\mathrm{N}$ and $\mathrm{K}$ nutrients leaching, mostly due to aplication rate of those nutrient, whereas type of fertilizer was not revealed significantly different. Meanwhile, $\mathrm{P}$ concentration in leachate water was significantly different among treatments. Leaching of $\mathrm{P}$ in the control treatment was very low because of $\mathrm{P}$ content of peat soil was low. The highest loss of $\mathrm{P}$ trough leaching rate is shown by the NPK treatment because NPK compound is belong to fast nutrient release fertilizer. CIRP and Pugam treatments showed low P loss trough leaching rates due to the slow release of P on CIRP and Pugam. The low leaching rates of CIRP and Pugam are also because of high content of $\mathrm{Al}$ and $\mathrm{Fe}$ as polyvalent cation that can promote new soil positive charges as site adsorption of $\mathrm{P}$. It can be concluded that fertilization with a slow release type of phosphate fertilizer and contain sesquioxide as source of polyvalent cations such as CIRP and Pugam can reduced the rate of phosphate loss trough leaching.
\end{abstract}

Keywords: peat, phosphate, leachate, leaching, nutrients, sorption

\section{ABSTRAK}

Tanah gambut memiliki karakteristik jerapan hara yang spesifik yang dipengaruhi oleh muatan tergantung $\mathrm{pH}$ tanah. Oleh karenanya, pengelolaan hara pada lahan semacam ini perlu pendekatan yang berbeda dibandingkan tanah mineral. Penelitian mengenai perbandingan pengaruh beberapa jenis pupuk fosfat terhadap kehilangan hara melalui pelindian pada tanah gambut telah dilakukan di rumah kaca dengan percobaan kolom. Penelitian bertujuan untuk mengevaluasi laju kehilangan hara makro primer pada tanah gambut dan mencari teknologi pemupukan yang mampu mengurangi laju pelindian. 
Penelitian menggunakan rancangan acak kelompok 14 perlakuan dengan 3 ulangan. Perlakuan adalah kontrol lengkap, kontrol parsial dan 4 jenis pupuk mengandung $\mathrm{P}$ yaitu SP-36, NPK-Ponska, Fosfat alam Chrismast (CIRP), dan Pugam masing-masing dengan 3 level dosis. Tanah gambut yang digunakan adalah gambut ombrogen dengan tingkat kematangan hemik diambil dari Kabupaten OKI Sumatera Selatan. Penyiraman dengan air bebas ion dilakukan 2 hari sekali dengan volume $350 \mathrm{ml} /$ pot. Hasil penelitian menunjukkan bahwa pelindian hara $\mathrm{N}$ dan $\mathrm{K}$ lebih dominan disebabkan karena dosis pupuk yang diaplikasikan, sedangkan jenis pupuk tidak menunjukkan perbedaan yang nyata. Sementara itu, konsentrasi hara $\mathrm{P}$ pada air leachate berbeda nyata antar perlakuan. Pelindian $\mathrm{P}$ pada perlakuan kontrol sangat rendah karena kandungan total $\mathrm{P}$ tanah gambut tergolong rendah. Laju pelindian tertinggi ditunjukkan oleh perlakuan NPK Ponska karena pupuk ini tergolong cepat larut. Perlakuan CIRP dan Pugam menunjukkan laju pelindian yang rendah karena tingkat kelarutan hara $\mathrm{P}$ yang rendah. Rendahnya laju pelindian juga disebabkan karena tingginya kandungan $\mathrm{Al}$ dan $\mathrm{Fe}$ sebagai kation polivalen yang bisa membentuk muatan positif baru yang berfungsi sebagai tapak jerapan P. Dapat disimpulkan bahwa pemupukan dengan jenis pupuk fosfat yang lambat larut dan dan mengandung sesquioksida sebagai sumber kation polivalen seperti fosfat alam Christmas dan Pugam dapat menghambat laju pelindian fosfat.

Kata kunci: gambut, fosfat, pelindian, leachate, unsur hara, jerapan

\section{PENDAHULUAN}

Lahan gambut adalah lahan yang terbentuk dari bahan organik sisa tanaman yang mati dengan ketebalan minimal $40 \mathrm{~cm}$ bila bahan organiknya telah terlapuk (saprik) atau $60 \mathrm{~cm}$ bila masih berupa bahan yang kasar (fibrik) (Soil Survey Staff, 2010). Lahan gambut merupakan bagian dari ekosistem rawa yang terbentuk pada landscap yang mengalami depresi. Luas lahan gambut di Indonesia diperkirakan sekitar 14,93 juta ha, tersebar di Sumatera, Kalimantan dan Papua (Ritung et al, 2015). Secara umum, gambut merupakan lahan marginal dan rapuh karena secara alamiah tidak mampu menopang pertumbuhan tanaman secara optimal serta rentan mengalami degradasi bila direklamasi.

Karakteristik kimia tanah gambut yang penting adalah kandungan senyawa humat dan asam-asam organik yang tinggi. Oleh karenanya, tanah gambut memiliki muatan negatif sangat tinggi sehingga kapasitas tukar kation (KTK) juga tinggi. Muatan negatif tanah gambut muncul dari proses disosiasi gugus karboksil, hidroksil dan fenol dari senyawa humat dan derivat asam-asam organik lainnya. Proses disosiasi terjadi bila $\mathrm{pH}$ tanah meningkat sehingga dikatakan sebagai muatan tergantung $\mathrm{pH}$ (Tan, 1998). Muatan negatif berfungsi sebagai tapak jerapan kation basa maupun asam (Al dan $\mathrm{H})$. Dalam kondisi alami tanah gambut didominasi oleh ion hidrogen $\left(\mathrm{H}^{+}\right)$. Kapasitas sangga ion hidrogen sangat besar sehingga sangat sedikit kation basa dalam tapak jerapan.

Tanah gambut didaerah tropis pada umumnya didominasi oleh gambut ombrogen yang miskin mineral, sehingga tanah gambut mengandung muatan positf sangat rendah. Oleh karenanya jerapan anion hara $\left(\mathrm{PO}_{4}\right.$ dan $\left.\mathrm{NO}_{3}\right)$ oleh tanah menjadi sangat rendah dan cenderung mengalami proses pelindian. Hal ini juga sangat menentukan dinamika anion hara dalam tanah. Gambut tropis pada umumnya juga tersusun dari bahan kayuan yang kaya dengan lignin. Hasil degradasi lignin dalam kondisi anaerob menghasilkan senyawa humat dan asam-asam fenolat yang bersifat fitotoksik (Kononova, 1968). Asam fenolat merusak sel akar dan menghambat pertumbuhan akar tanaman yang menyebabkan terganggunya serapan hara sehingga pertumbuhan tanaman terhambat (Stevenson, 1994; Rachim, 1995). 
Ditinjau dari proses pembentukannya, gambut ombrogen secara inheren memiliki kandungan unsur hara rendah sehingga bila dimanfaatkan untuk pertanian, pemupukan menjadi kebutuhan yang mutlak. Lahan gambut memerlukan tambahan hampir semua jenis unsur hara agar tanaman dapat tumbuh optimal. Unsur hara nitrogen $(\mathrm{N})$, fosfor $(\mathrm{P})$ dan kalium (K) adalah unsur hara makro primer yang paling banyak dibutuhkan oleh tanaman, sehingga pengelolaannya harus efektif dan efisien. Kendala yang dihadapi dalam pengelolaan hara pada tanah gambut adalah jerapan hara yang lemah sehingga hara yang diberikan melalui pupuk tidak efisien karena sebagian besar hilang melalui pelindian.

Unsur $\mathrm{N}$ merupakan komponen penting penyusun protein (asam amino) dan khlorofil. Bahan tanaman kering mengandung sekitar 2 sampai $4 \% \quad \mathrm{~N}$. Bentuk ion yang diserap oleh tanaman umumnya dalam bentuk $\mathrm{NO}_{3}{ }^{-}$dan $\mathrm{NH}_{4}{ }^{+}$ bagi tanaman padi sawah (Russell, 1973). Riley et al. (2001) menyatakan bahwa kehilangan $\mathrm{N}$ melalui leaching pada tanahtanah pertanian harus dikurangi karena berdampak langsung terhadap kesehatan manusia melalui kualitas air yang diminum, menyebabkan eutrofikasi pada perairan sungai dan danau, dan menyebabkan inefisiensi penggunaan pupuk. Kehilangan $\mathrm{N}$ melalui leaching dipengaruhi oleh faktor manajemen pemupukan N. Pemupukan terlalu awal menyebabkan banyak kehilangan N. Demikian pula dosis pemupukan $\mathrm{N}$ berpengaruh terhadap laju kehilangan $\mathrm{N}$ dari zone perakaran tanaman. Thomas et al. (2005) menyatakan bahwa $\mathrm{N}$ hilang melalui leaching di New Zealand sekitar $7 \%$ pada tanah mineral dari total pupuk yang diaplikasikandi lahan pertanian.

Pemupukan dengan pupuk yang mengandung hara fosfat adalah salah satu yang perlu perhatian khusus karena perilakunya sangat spesifik. Hara $\mathrm{P}$ larut dan diserap tanaman dalam bentuk anion fosfat $\left(\mathrm{PO}_{4}{ }^{-3}, \mathrm{HPO}_{4}{ }^{-2}\right.$ dan $\left.\mathrm{H}_{2} \mathrm{PO}_{4}^{-}\right)$. Oleh karenanya, bila pupuk fosfat diaplikasikan pada tanah gambut, maka anion fosfat tidak dijerap tanah tetapi tetap dalam larutan tanah sehingga mudah terlindi. Pelindian hara mengandung makna bahwa unsur hara bergerak menjauh dari zone perakaran tanaman mengikuti gerakan air tanah.Hasil penelitian Fox dan Kamprath menunjukkan hampir semua $\mathrm{P}$ yang ditambahkan ke tanah gambut akan hilang terlindi bila tidak diserap tanaman. Kehilangan melalui pelindian tersebut baru bisa dikurangi bila ditambahkan Al-clorida. Schoumans (2015) juga menyatakan bahwa kapasitas jerapan fosfat akan meningkat bila kandungan $\mathrm{Fe}$ dan $\mathrm{Al}$ semakin tinggi.

Proses kehilangan hara pada tanah gambut adalah melalui run-off bawah permukaan dan pelindian melewati lapisan tanah atau melalui saluran drainase karena lahan gambut memiliki topografi datar, (Chapman et al. 2005; Chardon and Schoumans, 2007; Heathwaite et al. 2005). Hasil penelitian menunjukkan bahwa laju kehilangan hara melalui pelindian bisa dikurangi dengan perlakuan tertentu. Penggunaan bahan alami seperti tanah mineral yang kaya besi seperti tanah laterit mampu mengurangi kelarutan asam-asam fenolat, meningkatkan produktivitas lahan gambut serta meningkatkan efektivitas dan efisiensi pupuk fosfat (Halim, 1987; Mario, 2002). Bahan alami yang kaya dengan kation polivalen tersebut dapat mengurangi sifat toksik asam fenolat, menyediakan unsur hara makro dan mikro dan meningkatkan jumlah tapak jerapan hara (Rachim, 1995; Sabiham, et al. 1997; Salampak, 1999). Fosfat alam yang dipakai sebagai sumber pupuk P pada lahan gambut memiliki efektivitas yang sama dengan SP36 (Hartatik et al. 2004; Subiksa et al. 1998). Abu sawmill dan terak baja juga dilaporkan memiliki pengaruh yang baik terhadap produktivitas lahan gambut (Subiksa et al. 1997). Walaupun lahan gambut memiliki banyak kendala yang berkaitan dengan sifat fisik dan kimia tanah, namun Agus dan Subiksa (2008) menyatakan bahwa dengan teknologi 
pengelolaan tanah dan air lahan gambut bisa dimanfaatkan menjadi lahan yang produktif.

Penelitian bertujuan untuk mengevaluasi laju pelindian unsur hara makro primer $\mathrm{N}, \mathrm{P}$ dan $\mathrm{K}$ pada tanah gambut dan mencari teknologi pemupukan yang mampu mengurangi laju pelindian hara tersebut serta meningkatkan efektivitas dan efisiensi pemupukan.

\section{BAHAN DAN METODE}

Penelitian dilakukan di rumah kaca Balai Penelitian Tanah dengan metode percobaan kolom. Penelitian menggunakan rancangan acak kelompok dengan 14 perlakuan dengan 3 ulangan. Perlakuan adalah 4 jenis pupuk mengandung $P$ yaitu SP-36, NPK majemuk Ponska, Fosfat alam Christmas dan Pugam masing-masing dengan 3 level dosis yaitu 1,25 g/pot, 2,50 g/pot dan 3,75 g/pot. Sebagai pembanding adalah perlakuan kontrol lengkap yaitu perlakuan tanpa pupuk dan kontrol parsial yaitu perlakuan $\mathrm{N}$ dan $\mathrm{K}$ tanpa pupuk fosfat (Tabel 1). Pupuk N dan K juga diberikan dengan dosis yang sama dengan $\mathrm{P}$ yaitu $1,25 \mathrm{~g} / \mathrm{pot}, 2,50 \mathrm{~g} / \mathrm{pot}$ dan 3,75 g/pot masing-masing dalam bentuk $\mathrm{N}$ dan $\mathrm{K}_{2} \mathrm{O}$. Sumber hara $\mathrm{N}$ adalah pupuk urea dan sumber hara $\mathrm{K}$ adalah $\mathrm{KCl}$ kecuali pada perlakuan NPK karena sudah mengandung $\mathrm{N}$ dan $\mathrm{K}$.

Tabel 1. Komposisi perlakuan

\begin{tabular}{|c|c|c|c|c|}
\hline \multirow{2}{*}{ No. } & \multirow{2}{*}{ Perlakuan } & \multicolumn{3}{|c|}{ Dosis Pupuk (g/pot) } \\
\hline & & $\mathrm{P}_{2} \mathrm{O}_{5}$ & $\mathrm{~N}^{*}$ & $\mathrm{~K}_{2} \mathrm{O} * *$ \\
\hline 1 & Kontrol (CC) & 0 & 0 & 0 \\
\hline 2 & Kontrol Parsial (PC) & 0 & 2,50 & 2,50 \\
\hline 3 & SP36-1 & 1,25 & 1,25 & 1,25 \\
\hline 4 & SP36-2 & 2,50 & 2,50 & 2,50 \\
\hline 5 & SP36-3 & 3,75 & 3,75 & 3,75 \\
\hline 6 & NPK-1 & 1,25 & 1,25 & 1,25 \\
\hline 7 & NPK-2 & 2,50 & 2,50 & 2,50 \\
\hline 8 & NPK-3 & 3,75 & 3,75 & 3,75 \\
\hline 9 & CIRP-1 & 1,25 & 1,25 & 1,25 \\
\hline 10 & CIRP-2 & 2,50 & 2,50 & 2,50 \\
\hline 11 & CIRP-3 & 3,75 & 3,75 & 3,75 \\
\hline 12 & Pugam-1 & 1,25 & 1,25 & 1,25 \\
\hline 13 & Pugam-2 & 2,50 & 2,50 & 2,50 \\
\hline 14 & Pugam-3 & 3,75 & 3,75 & 3,75 \\
\hline
\end{tabular}

Keterangan: *) Sumber N dari urea kecuali perlakuan NPK; **) Sumber K dari KCl kecuali perlakuan NPK

Penyiraman dilakukan menggunakan air bebas ion (demineralisasi) setiap 2 hari sekali dengan volume $300 \mathrm{ml} /$ pot. Air yang melewati kolom tanah akan tertampung di dasar pot sebagai air bebas. Pengambilan contoh air yang tertampung di dasar pot (air leachate) dilakukan 3 kali yaitu pada inkubasi 2 minggu, 4 minggu dan 6 minggu. Pengambilan air leachate dilakukan dengan mengalirkannya melalui selang yang dipasang pada dasar pot.
Jumlah air leachate yang diperoleh ditakar untuk mengetahui volumenya. Contoh air leachate yang sudah diambil selanjutnya dianalisis di laboratorium kimia untuk mengetahui kandungan hara makro primer $\mathrm{N}$, P dan $\mathrm{K}$. Unsur hara $\mathrm{N}$ dianalisis dalam bentuk kation $\mathrm{NH}_{4}^{+}$dan anion $\mathrm{NO}_{3}{ }^{-}$. Sedangkan unsur hara $\mathrm{P}$ dianalisis dalam bentuk anion $\mathrm{PO}_{4}^{-3}$ dan unsur hara $\mathrm{K}$ dalam bentuk kation $\mathrm{K}^{+}$. 
HASIL DAN PEMBAHASAN

\section{Karakteristik Tanah}

Hasil analisis tanah gambut yang digunakan untuk penelitian ditampilkan pada Tabel 2. Hasil analisis menunjukkan bahwa tanah gambut memiliki $\mathrm{pH} 3,7$ tergolong sangat randah. Sumber kemasaman tanah gambut adalah asam- asam organik alifatik maupun aromatik sebagai hasil proses degradasi selulosa dan lignin dari gambut. Hal ini juga terlihat dari tingginya kadar asam humat dan asam fulvat dari contoh gambut yang dianalisis. Tingkat kematangan gambut tergolong hemik dengan kadar karbon organik 27\% dan total $\mathrm{N} 0,19 \%$ sehingga $\mathrm{C} / \mathrm{N}$ ratio tergolong sangat tinggi.

Tabel 2. Hasil analisis contoh tanah bulk gambut asal Kabupaten Ogan Komering Ilir Sumatera Selatan.

\begin{tabular}{|c|c|c|c|}
\hline No. & Parameter & Nilai & Keterangan \\
\hline \multirow[t]{2}{*}{1} & $\mathrm{pH}: \mathrm{H}_{2} \mathrm{O}$ & 3.7 & Sangat rendah \\
\hline & $\mathrm{KCl}$ & 3.1 & Sangat rendah \\
\hline \multirow[t]{4}{*}{2} & Bahan Organik: & & \\
\hline & $\mathrm{C}(\%)$ & 27 & Tinggi \\
\hline & $\mathrm{N}(\%)$ & 0.19 & Rendah \\
\hline & $\mathrm{C} / \mathrm{N}$ & 142 & Tinggi \\
\hline \multirow[t]{3}{*}{3} & Ekstrak $\mathrm{HCl} 25 \%$ : & & \\
\hline & $\mathrm{P}_{2} \mathrm{O}_{5}(\mathrm{mg} / 100 \mathrm{~g})$ & 12 & Rendah \\
\hline & $\mathrm{K}_{2} \mathrm{O}(\mathrm{mg} / 100 \mathrm{~g})$ & 9 & Rendah \\
\hline \multirow[t]{6}{*}{4} & Nilai Tukar Kation & & \\
\hline & $\mathrm{Ca}\left(\mathrm{cmol}_{(+)} / \mathrm{kg}\right)$ & 3.60 & Rendah \\
\hline & $\mathrm{Mg}\left(\mathrm{cmol}_{(+)} / \mathrm{kg}\right)$ & 1.65 & Rendah \\
\hline & $\mathrm{K}\left(\mathrm{cmol}_{(+)} / \mathrm{kg}\right)$ & 0.85 & Rendah \\
\hline & $\mathrm{Na}\left(\mathrm{cmol}_{(+)} / \mathrm{kg}\right)$ & 0.70 & Rendah \\
\hline & Jumlah $\left(\mathrm{cmol}_{(+)} / \mathrm{kg}\right)$ & 6.80 & Rendah \\
\hline 5 & $\mathrm{KTK}\left(\mathrm{cmol}_{(+)} / \mathrm{kg}\right)$ & 138 & Sangat tinggi \\
\hline 6 & $\mathrm{~KB} *(\%)$ & 5 & Sangat rendah \\
\hline \multirow[t]{5}{*}{7} & Ekstrak DTPA: & & \\
\hline & $\mathrm{Fe}(\mathrm{ppm})$ & 365.4 & Sedang \\
\hline & Mn (ppm) & 14.6 & Rendah \\
\hline & $\mathrm{Cu}(\mathrm{ppm})$ & 2.4 & Rendah \\
\hline & $\mathrm{Zn}(\mathrm{ppm})$ & 4.5 & Rendah \\
\hline \multirow[t]{3}{*}{8} & Asam Organik: & & \\
\hline & Humat (\%) & 11.20 & Tinggi \\
\hline & Fulvat (\%) & 4.65 & Tinggi \\
\hline
\end{tabular}

Seperti tanah organik pada umumnya, KTK tanah gambut dari OKI ini tergolong sangat tinggi (138 $\left.\mathrm{cmol} \mathrm{kg}^{-1}\right)$. Muatan negatif gambut umumnya berasal dari proses disosiasi gugus karboksil, hidroksil, dan fenol. Dari segi kapasitas, kemampuan menjerap kation sangat besar, namun kekuatan jerapannya (sorption power) tergolong lemah sehingga kation hara seperti $\mathrm{Ca}, \mathrm{Mg}$ dan $\mathrm{K}$ mudah terlindi. Muatan negatif yang besar juga menyebabkan unsur hara yang bermuatan negatif seperti fosfat, sulfat dan nitrat akan mudah terlindi. Komposisi kation basa pada tapak jerapan negatif didominasi oleh $\mathrm{Ca}$, namun jumlahnya masih tergolong sangat rendah jika dibandingkan dengan kation hidrogen. Oleh karenanya, kejenuhan basa menjadi sangat rendah. Kondisi ini memerlukan upaya ameliorasi dengan agar keseimbangan kation lebih baik.

Kandungan hara $\mathrm{P}$ dan $\mathrm{K}$ yang yang dapat diekstrak oleh $\mathrm{HCl} 25 \%$ tergolong sangat rendah. Kedua unsur hara ini diperlukan dalam jumlah banyak oleh tanaman sehingga untuk mencukupi 
kebutuhan tanaman harus dilakukan adalah SP-36, TSP, fosfat alam dan pupuk pemupukan. Sumber pupuk P yang umum majemuk NPK.

Tabel 3. Konsentrasi hara makro primer dan makro sekunder pada air leachate setelah 28 hari inkubasi

\begin{tabular}{lllcl}
\hline \multirow{2}{*}{ Perlakuan } & \multicolumn{5}{c}{ Konsentrasi hara pada air leachate (ppm) } \\
\cline { 2 - 5 } & \multicolumn{1}{c}{$\mathrm{NH}_{4}$} & \multicolumn{1}{c}{$\mathrm{NO}_{3}$} & \multicolumn{1}{c}{$\mathrm{PO}_{4}$} & $\mathrm{~K}$ \\
\hline $\mathrm{CC}$ & $13,28 \mathrm{~d}$ & $30,41 \mathrm{f}$ & $3,67 \mathrm{~g}$ & $18,67 \mathrm{~g}$ \\
$\mathrm{PC}$ & $25,30 \mathrm{ab}$ & $57,15 \mathrm{ab}$ & $4,67 \mathrm{~g}$ & $47,36 \mathrm{bcd}$ \\
$\mathrm{SP} 36-1$ & $15,49 \mathrm{~cd}$ & $37,67 \mathrm{def}$ & $20,33 \mathrm{def}$ & $36,67 \mathrm{ef}$ \\
SP36-2 & $19,20 \mathrm{bcd}$ & $41,34 \mathrm{def}$ & $31,00 \mathrm{~cd}$ & $42,44 \mathrm{def}$ \\
SP36-3 & $24,05 \mathrm{bc}$ & $60,00 \mathrm{a}$ & $40,33 \mathrm{bc}$ & $53,33 \mathrm{bc}$ \\
NPK-1 & $20,09 \mathrm{bcd}$ & $32,79 \mathrm{f}$ & $30,67 \mathrm{~cd}$ & $40,88 \mathrm{def}$ \\
NPK-2 & $20,49 \mathrm{bcd}$ & $46,57 \mathrm{cde}$ & $52,00 \mathrm{~b}$ & $56,07 \mathrm{~b}$ \\
NPK-3 & $25,87 \mathrm{ab}$ & $58,05 \mathrm{ab}$ & $75,33 \mathrm{a}$ & $75,00 \mathrm{a}$ \\
CIRP-1 & $19,52 \mathrm{bcd}$ & $36,53 \mathrm{ef}$ & $11,33 \mathrm{efg}$ & $35,70 \mathrm{f}$ \\
CIRP-2 & $24,59 \mathrm{~b}$ & $40,89 \mathrm{def}$ & $14,67 \mathrm{efg}$ & $44,81 \mathrm{def}$ \\
CIRP-3 & $33,09 \mathrm{a}$ & $54,33 \mathrm{abc}$ & $21,00 \mathrm{de}$ & $55,70 \mathrm{~b}$ \\
Pugam-1 & $17,25 \mathrm{bcd}$ & $34,67 \mathrm{f}$ & $6,69 \mathrm{fg}$ & $38,67 \mathrm{def}$ \\
Pugam-2 & $20,37 \mathrm{bcd}$ & $41,05 \mathrm{def}$ & $11,33 \mathrm{efg}$ & $46,96 \mathrm{cde}$ \\
Pugam-3 & $24,76 \mathrm{~b}$ & $48,33 \mathrm{bcd}$ & $11,67 \mathrm{efg}$ & $53,33 \mathrm{bc}$ \\
\hline Kef
\end{tabular}

Keterangan: angka pada satu kolom yang sama dan diikuti huruf yang sama tidak menunjukkan perbedaan nyata

\section{Pelindian Nitrogen}

Unsur hara nitrogen tergolong unsur hara yang sangat mobil dalam tanah maupun tanaman. Pergerakan hara menuju akar terjadi karena aliran masa yang dipicu oleh adanya proses evapotranspirasi. Namun pergerakan hara menjauh dari zone perakaran (pelindian) disebabkan karena conduktivitas hidrolik yang tinggi dari tanah gambut. Kelebihan air di zone perakaran karena curah hujan yang tinggi.

Apabila tanah diberikan hara nitrogen dalam bentuk pupuk urea, maka didalam tanah akan terjadi proses hidrolisis urea menjadi amonium $\left(\mathrm{NH}_{4}{ }^{+}\right)$yang larut air. Selanjutnya amonium mengalami proses nitrifikasi menjadi nitrat $\left(\mathrm{NO}_{3}{ }^{-}\right)$. Proporsi amonium dan nitrat dalam tanah dipengaruhi oleh laju hidrolisis urea dan laju proses nitrifikasi. Tillman dan Scotes (1991) menyatakan bahwa pergerakan $\mathrm{NH}_{4}{ }^{+}$, selain dipengaruhi oleh faktor-faktor pergerakan (aliran massa dan difusi) secara umum, juga ditentukan oleh besarnya hidrolisis urea (seperti enzim urease, air tanah) dan faktor penentu nitrifikasi (seperti $\mathrm{pH}$, air tanah, aktivitas bakteri nitrifikasi).
Hasil analisis $\mathrm{NH}_{4}$ dan $\mathrm{NO}_{3}$ dalam air leachate ditampilkan pada Tabel 3. Hasil penelitian menunjukkan bahwa secara umum $\mathrm{NH}_{4}$ terlindi lebih rendah dibandingkan dengan $\mathrm{NO}_{3}$. Hal ini berkaitan dengan adanya jerapan oleh muatan negatif tanah terhadap kation $\mathrm{NH}_{4}$. Wild (1981) menyatakan bahwa kation $\mathrm{NH}_{4}{ }^{+}$merupakan kation yang dapat teradsorbsi di permukaan koloid tanah, sehingga gerakannya akan lebih kecil dibandingkan $\mathrm{NO}_{3}{ }^{-}$yang senantiasa bebas di larutan tanah. Killpack and Buchholz (2017) menyatakan bahwa bentuk $\mathrm{NO}_{3}$ akan lebih banyak mengalami leaching karena mobilitasnya tinggi dalam larutan tanah. Sedangkan $\mathrm{NH}_{4}$ pada umumnya tidak mengalami leaching. Namun kenyataannya $\mathrm{NH}_{4}$ kalau di tanah gambut mengalami pelindian cukup besar walaupun tidak sebesar $\mathrm{NO}_{3}$. Hal ini disebabkan karena tanah gambut memiliki daya sangga keasaman yang besar.

Konsentrasi $\mathrm{NH}_{4}$ pada air leachate berbeda berdasarkan dosis $\mathrm{N}$ yang diberikan. Makin tinggi dosis $\mathrm{N}$, maka kandungan $\mathrm{NH}_{4}$ pada leachate makin tinggi. 
Walaupun tanah gambut memiliki muatan negatif yang besar (terekstrak amonium acetat $\mathrm{pH}$ 7), namun muatan tanah gambut adalah muatan tergantung $\mathrm{pH}$ dimana muatan negatif tanah akan meningkat bila $\mathrm{pH}$ tanah meningkat misalnya dengan pengapuran atau dikeringkan. Kation $\mathrm{NH}_{4}$ yang tidak berhasil menempati tapak jerapan akan tetap berada pada larutan tanah dan mengalami pelindian bila air tanah bergerak vertical maupun horizontal. Dari data tersebut juga dapat dilihat bahwa jenis pupuk tidak berpengaruh terhadap konsentrasi $\mathrm{NH}_{4}$ pada leachate. Hal ini menunjukkan bahwa ion amonium $\left(\mathrm{NH}_{4}\right)$ tidak dipengaruhi oleh jenis pupuk yang diberikan, tetapi dipengaruhi oleh dosis $\mathrm{N}$ yang diberikan. Makin banyak dosis $\mathrm{N}$ maka makin banyak $\mathrm{NH}_{4}$ yang hilang melalui pencucian.

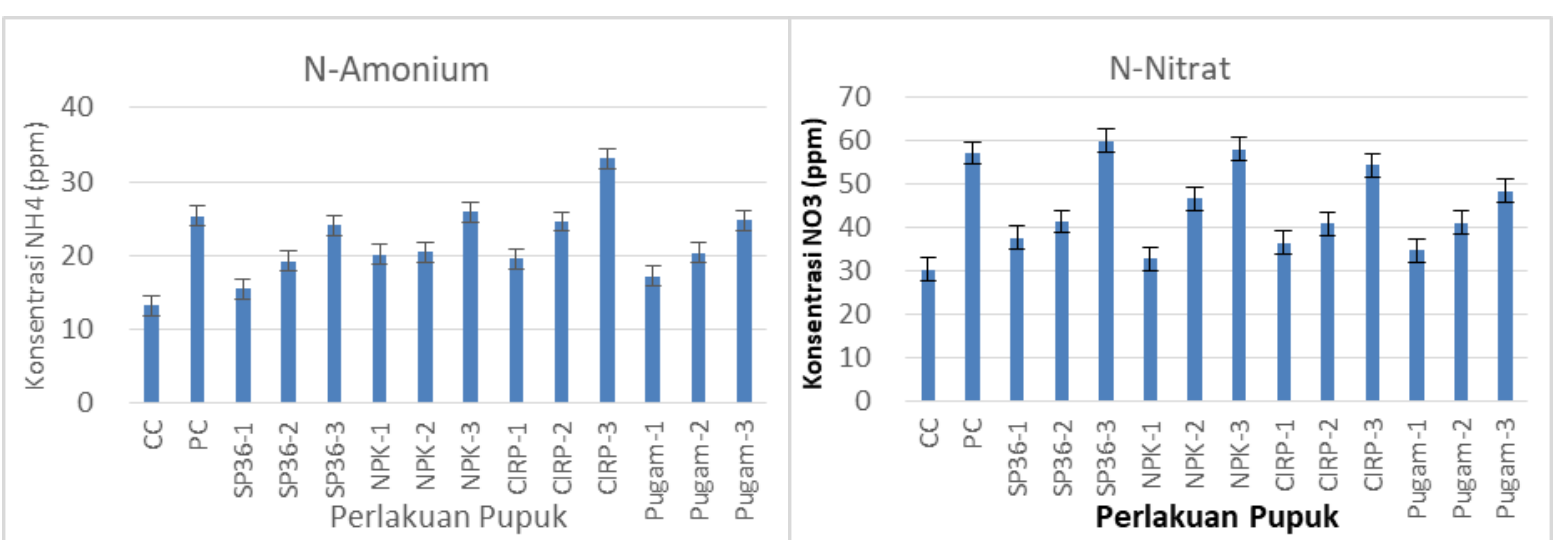

Gambar 1. Konsentrasi N-amonium dan N-nitrat pada air leachate pada inkubasi 28 hari.

Dari hasil 3 kali pengamatan konsentrasi hara, konsentrasi Amonium pada air leachate menunjukkan dinamika dan pola yang hampir sama (Gambar 2). Demikian pula halnya dengan dinamika dan pola ion nitrat $\left(\mathrm{NO}_{3}\right)$ walaupun ada kecenderungan pada pengamatan saat 42 hari inkubasi konsentrasinya terlihat sedikit menurun (Gambar 3). Dari gambar yang ditampilkan tersebut, tidak ada perbedaan nyata konsentrasi $\mathrm{NH}_{4}$ maupun $\mathrm{NO}_{3}$ antar perlakuan pupuk, kecuali dengan perlakuan kontrol karena pada perlakuan ini tidak diberikan $\mathrm{N}$ sama sekali.

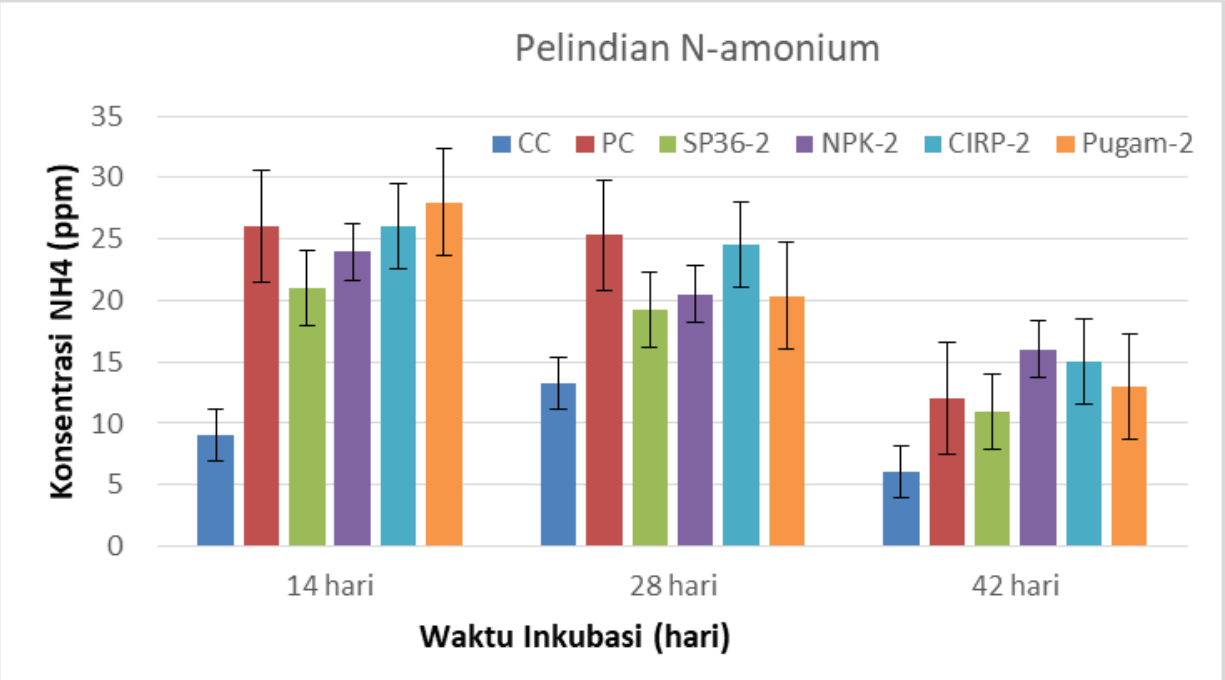

Gambar 2. Dinamika konsentrasi hara N-Amonium pada air leachate pada inkubasi 14 hari, 28 hari dan 42 hari 


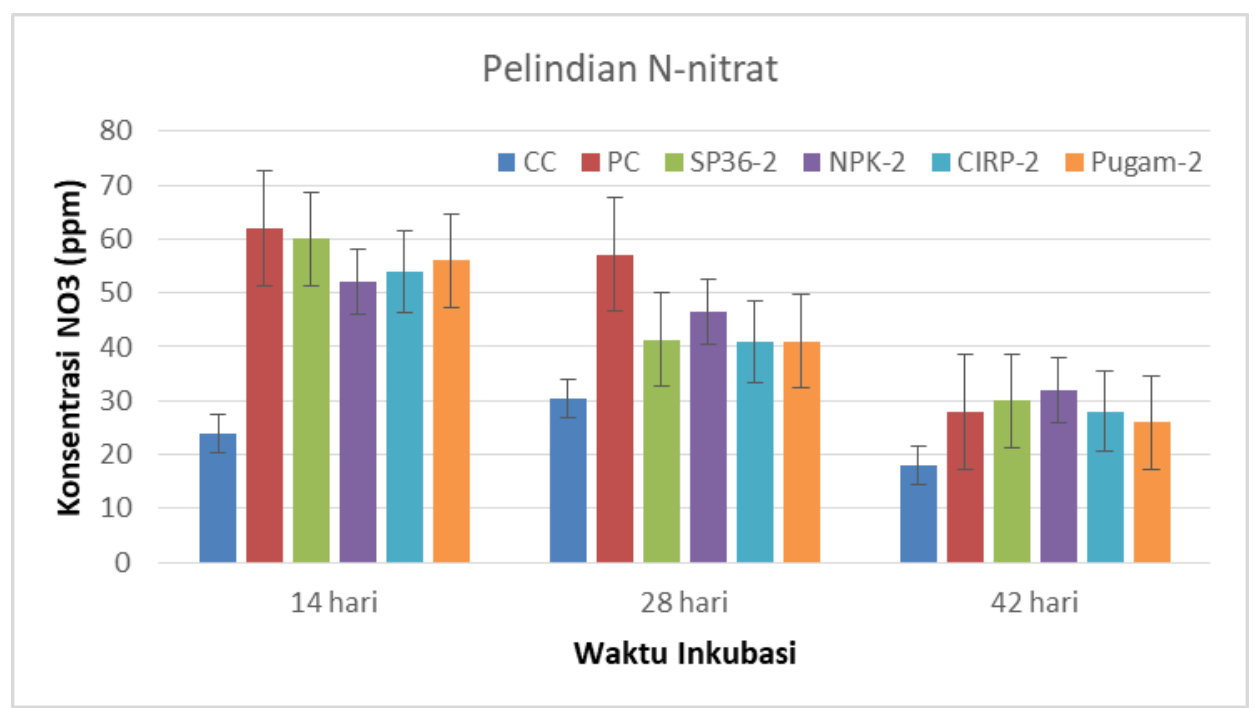

Gambar 3. Dinamika konsentrasi hara N-Nitrat pada air leachate pada inkubasi 14 hari, 28 hari dan 42 hari

Berbeda dengan $\mathrm{NH}_{4}$, anion $\mathrm{NO}_{3}$ tidak terikat pada tapak jerapan negatif sehingga konsentrasi $\mathrm{NO}_{3}$ lebih tinggi dibandingkan dengan kation $\mathrm{NH}_{4}$. Konsentrasi anion $\mathrm{NO}_{3}$ pada leachate dipengaruhi oleh dosis $\mathrm{N}$ yang diberikan. Diantara jenis pupuk, tidak ada perbedaan yang nyata konsentrasi $\mathrm{NO}_{3}$ pada dosis $\mathrm{N}$ yang sama. Namun ada kecenderungan pada dosis $\mathrm{N}$ yang tinggi, konsentrasi $\mathrm{NO}_{3}$ pada air leachate lebih rendah pada perlakuan Pugam. Muatan positif yang terbentuk karena tanah gambut akibat adanya ikatan tidak jenuh antara kation polivalen dengan asam organik. Muatan positif baru tersebut bisa mengikat sementara anion $\mathrm{NO}_{3}$ sehingga konsentrasi pada leachate menjadi lebih rendah dibandingkan dengan perlakuan jenis pupuk fosfat lainnya.

\section{Pelindian Hara Fosfat}

Anion fosfat $\left(\mathrm{H}_{2} \mathrm{PO}_{4}{ }^{-}, \mathrm{HPO}_{4}{ }^{2-}\right.$ dan $\mathrm{PO}_{4}{ }^{3-}$ ) adalah bentuk hara fosfat yang larut dan terjerap pada muatan positif tanah. Hasil analisis konsentrasi PO4 pada air leachate ditampilkan pada Tabel 3 dan ilustrasi perbandingan pelindian $\mathrm{PO} 4$ pada tanah gambut ditampilkan pada Gmbar 4. Konsentrasi PO4 menunjukkan perbedaan yang nyata akibat perlakuan jenis pupuk. Konsentrasi $\mathrm{P}$ tertinggi ditunjukkan oleh perlakuan pemupukan NPK majemuk
Ponska, diikuti oleh perlakuan pupuk SP36, fosfat alam CIRP dan pupuk Pugam, masing-masing pada dosis pemupukan yang sama. Hal ini berhubungan dengan daya larut masing-masing jenis pupuk. NPK majemuk adalah pupuk yang larut dalam air dengan cepat sehingga konsentrasi $\mathrm{P}$ pada larutan tanah menjadi tinggi. Pupuk SP-36 juga tergolong pupuk $\mathrm{P}$ yang mudah larut, tetapi tingkat kelarutannya lebih rendah dibandingkan dengan NPK majemuk. Pupuk fosfat alam CIRP adalah fosfat alam grade $\mathrm{C}$ yang memiliki kandungan sesquioksida ( $\mathrm{Fe}$ dan $\mathrm{Al}$ ) yang tinggi dan kelarutan $\mathrm{P}$ lebih rendah dari SP-36. Sumber fosfat ini memiliki efek ganda untuk menekan kelarutan $\mathrm{P}$ dalam air leachate. Selain karena kelarutan $\mathrm{P}$ yang rendah, sesquioksida adalah sumber kation polivalen yang bisa membentuk muatan positif pada tanah gambut sehingga mampu menjerap ion fosfat. Pupuk yang mengandung fosfat lainnya yaitu fosfat alam Chrismast (CIRP) dan Pugam memiliki tingkat kelarutan yang rendah sehingga laju kehilangan fosfat melalui pelindian relatif lebih rendah dibandingkan pupuk NPK.

Dari hasil 3 kali analisis kandungan leachate, Pupuk NPK selalu menunjukkan konsentrasi $\mathrm{PO}_{4}$ paling tinggi terkait dengn tingkat kelarutan pupuk NPK yang 
tergolong cepat. Sebaliknya CIRP dan Pugam selalu paling rendah karena tingkat kelarutan yang rendah dan dibantu oleh keberadaan $\mathrm{Fe}$ dan $\mathrm{Al}$ yang membentuk muatan positif sehingga mampu menjerap anion P. Hal ini sesuai dengan hasil penelitian Forsman dan Kjaergarrd (2014) hasil penelitian Schoumans (2015)

Pugam adalah pupuk fosfat yang khusus diformulasi untuk tanah gambut mengandung sekitar $13 \% \mathrm{P}_{2} \mathrm{O}_{5}$. Pugam juga memiliki tingkat kelarutan yang rendah sehingga hara fosfat dilepas secara perlahan ke dalam larutan tanah. Pugam memiliki kandungan sesquioksida yang lebih tinggi dibandingkan dengan CIRP. Pugam juga mengandung $\mathrm{Fe}, \mathrm{Al}, \mathrm{Cu}$ dan $\mathrm{Zn}$ yang juga berfungsi sebagai sumber muatan positif setelah berinteraksi dengan asam-asam organik tanah. Oleh karenanya, Pugam memiliki kemampuan menjerap $\mathrm{P}$ lebih tinggi dibandingkan dengan perlakuan lainnya. Dengan rendahnya potensi kehilangan melalui pelindian, maka CIRP dan pupuk Pugam lebih cocok digunakan pada lahan gambut untuk menekan laju kehilangan $\mathrm{P}$ melalui pelindian dibandingkan menggunakan NPK majemuk. Dengan demikian maka tanaman juga memiliki peluang lebih tinggi untuk menyerap hara $\mathrm{P}$ untuk pertumbuhan yang lebih baik dan meningkatkan efisiensi pemupukan $\mathrm{P}$.

Forsman dan Kjaergaard, (2014) menyatakan bahwa pelindian $\mathrm{P}$ dari tanah gambut ditentukan oleh kelarutan besi yang dapat diprediksi dari $\mathrm{Fe} / \mathrm{P}$ ratio. Makin tinggi $\mathrm{Fe} / \mathrm{P}$ maka pelindian $\mathrm{P}$ makin kecil. Hasil penelitian Schoumans (2015) menyatakan bahwa kandungan $\mathrm{Al}$ dan $\mathrm{Fe}$ pada tanah gambut berkorelasi sangat nyata dengan jerapan $\mathrm{P}$, dimana makin tinggi kandungan $\mathrm{Al}$ dan $\mathrm{Fe}$ maka kapasitas jerapan $\mathrm{P}$ (P sorption capacity) makin tinggi (Gambar 6). CIRP dan Pugam adalah pupuk $P$ yang yang mengandung al dan Fe yang tinggi. Dalam kondisi tanah gambut yang sangat masam maka $\mathrm{Al}$ dan $\mathrm{Fe}$ tersebut akan melarut dan membentuk ikatan koordinasi dengan ligan organik membentuk khelat. Sisa muatan positif Al dan $\mathrm{Fe}$ menjadi tapak jerapan baru untuk mengikat anion fosfat sehingga mengurangi laju pelindian.

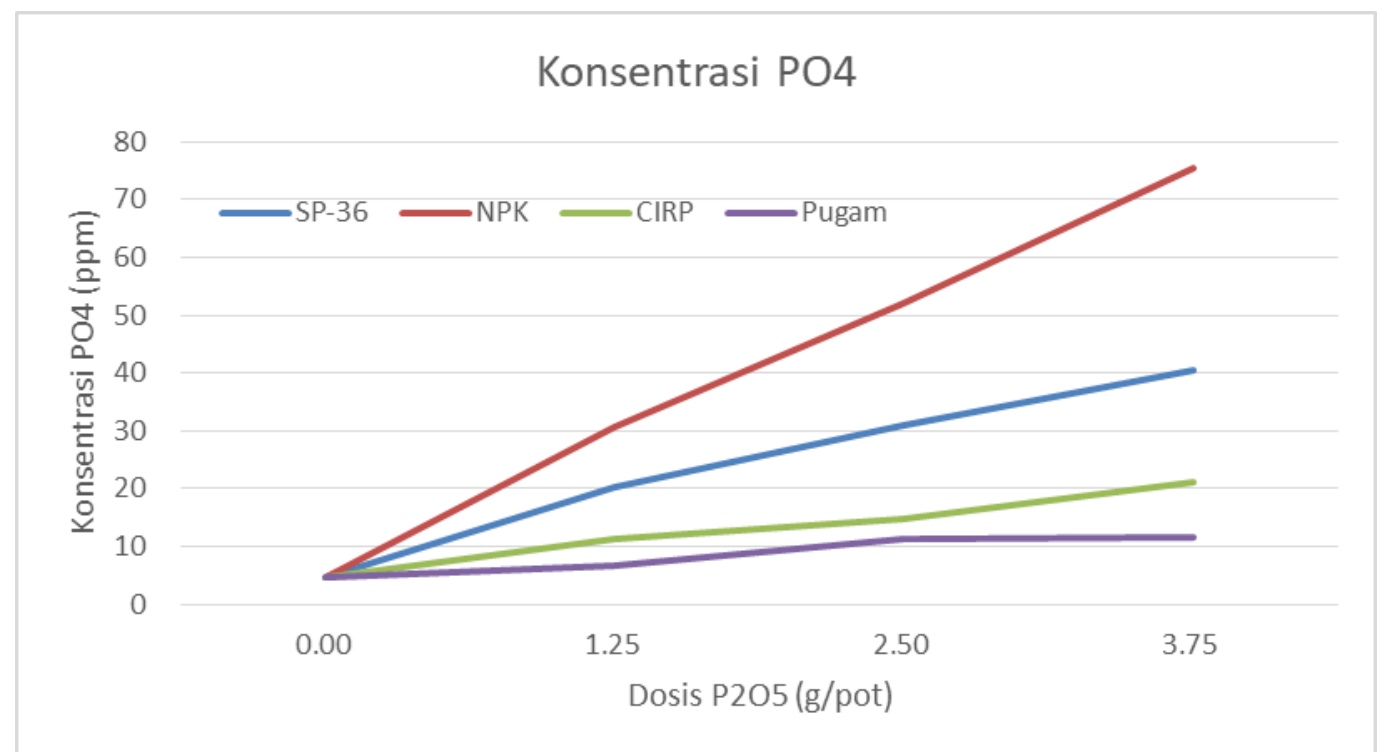

Gambar 4. Hubungan antara dosis $\mathrm{P}$ dan konsentrasi anion fosfat (PO4) air leachate setelah inkubasi 28 hari. 


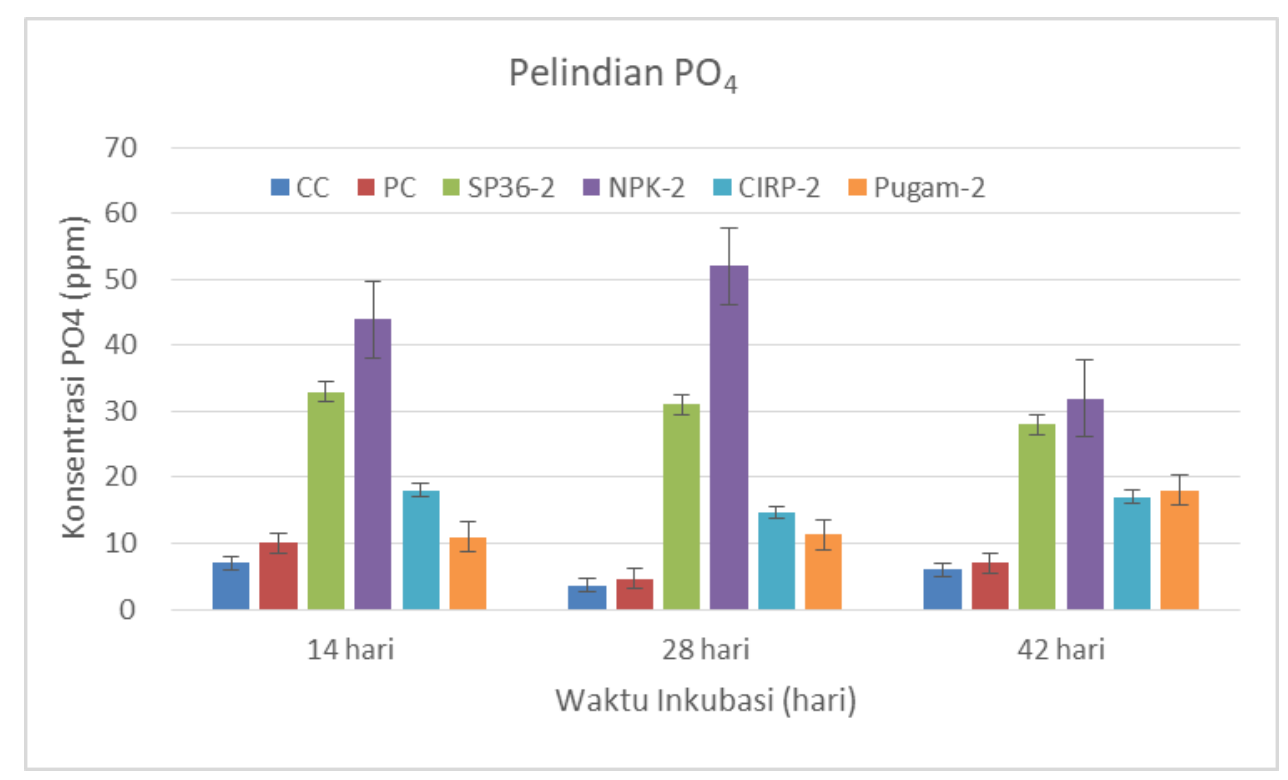

Gambar 5. Dinamika konsentrasi hara P air leachate pada inkubasi 14 hari, 28 hari dan 42 hari.

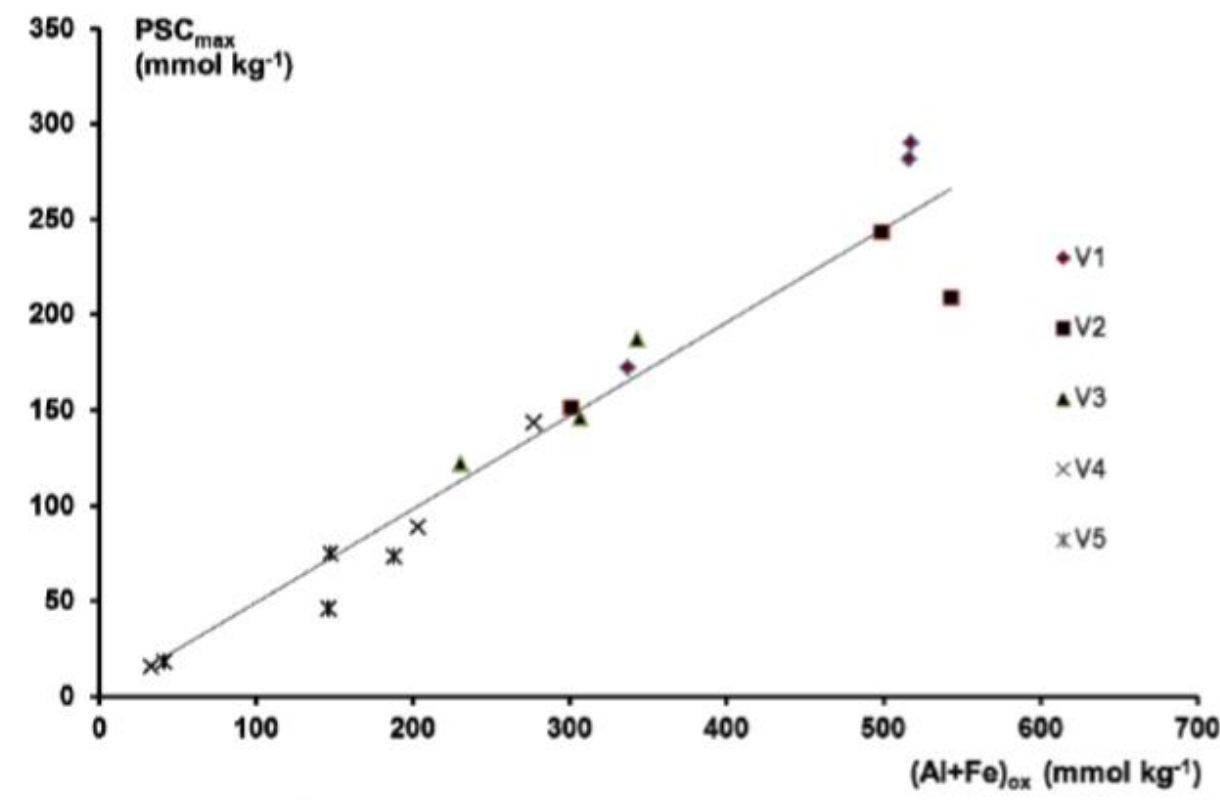

Gambar 6 . Hubungan antara kandungan $\mathrm{Al}+\mathrm{Fe}$ dan kapasitas jerapan fosfat pada tanah gambut (Schoumans, 2015)

\section{Pelindian Hara Kalium}

Hara Kalium (K) larut dan terjerap dalam tanah serta diserap tanaman dalam bentuk kation $\mathrm{K}^{+}$. Karena tanah gambut bermuatan negatif, maka kation $\mathrm{K}$ akan terjerap oleh muatan negatif tanah secara elektrostatik. Namun, tanah gambut dikenal memiliki daya sangga yang kuat sehingga $\mathrm{K}$ dijerap hanya sementara karena $\mathrm{H}^{+}$akan kembali mendesak $\mathrm{K}$ melalui aksi massa sehingga mudah terlindi. Jumlah hara $\mathrm{K}$ yang terlindi dipengaruhi oleh dosis $\mathrm{K}$ yang diberikan, dimana makin tinggi dosis $\mathrm{K}$ yang diberikan maka makin banyak $\mathrm{K}$ yang terlindi. Perlakuan beragam jenis pupuk nampak tidak berpengaruh nyata, namun ada kecenderungan perlakuan pemupukan NPK majemuk terlihat konsentrasi K pada leachate paling tinggi. 
Dinamika kalium dalam larutan tanah dipengaruhi oleh muatan negatif tanah dimana makin tinggi muatan negatifnya maka kation $\mathrm{K}$ terjerap lebih banyak. Pergerakan K dalam larutan tanah terjadi melalui mekanisme aliran masa dan difusi. Oleh karenanya, kehilangan hara $\mathrm{K}$ melalui pelindian, semata-mata dipengaruhi oleh jumlah atau dosis $\mathrm{K}$ yang diberikan melalui pupuk. Hasil penelitian menunjukkan bahwa $\mathrm{K}$ dari pupuk NPK mengalami pelindian lebih besar dibandingkan pupuk lainnya setelah masa inkubasi 28 hari. Sedangkan pada masa inkubasi 14 hari, pelindian K pada pupuk
NPK lebih rendah dari perlakuan lainnya yang menggunakan $\mathrm{KCl}$ sebagai sumber $\mathrm{K}$. Hal ini disebabkan karena $\mathrm{KCl}$ sangat mudah larut sehingga begitu diaplikasikan langsung larut dan terlindi bila tidak dijerap oleh muatan negatif tanah. Perbedaan pelindian yang paling nyata disebabkan perlakuan dosis pupuk K. Makin tinggi dosis pupuk yang diberikaan, maka pelindian $\mathrm{K}$ semakin besar. Pelindian $\mathrm{K}$ pada inkubasi 14 hari dan 28 hari menunjukkan konsentrasi $\mathrm{K}$ yang relatif sama, Sedaangkan setelah inkubasi 42 hari, konsentrasi $\mathrm{K}$ pada air leachate makin berkurang (Gambar 8 ).

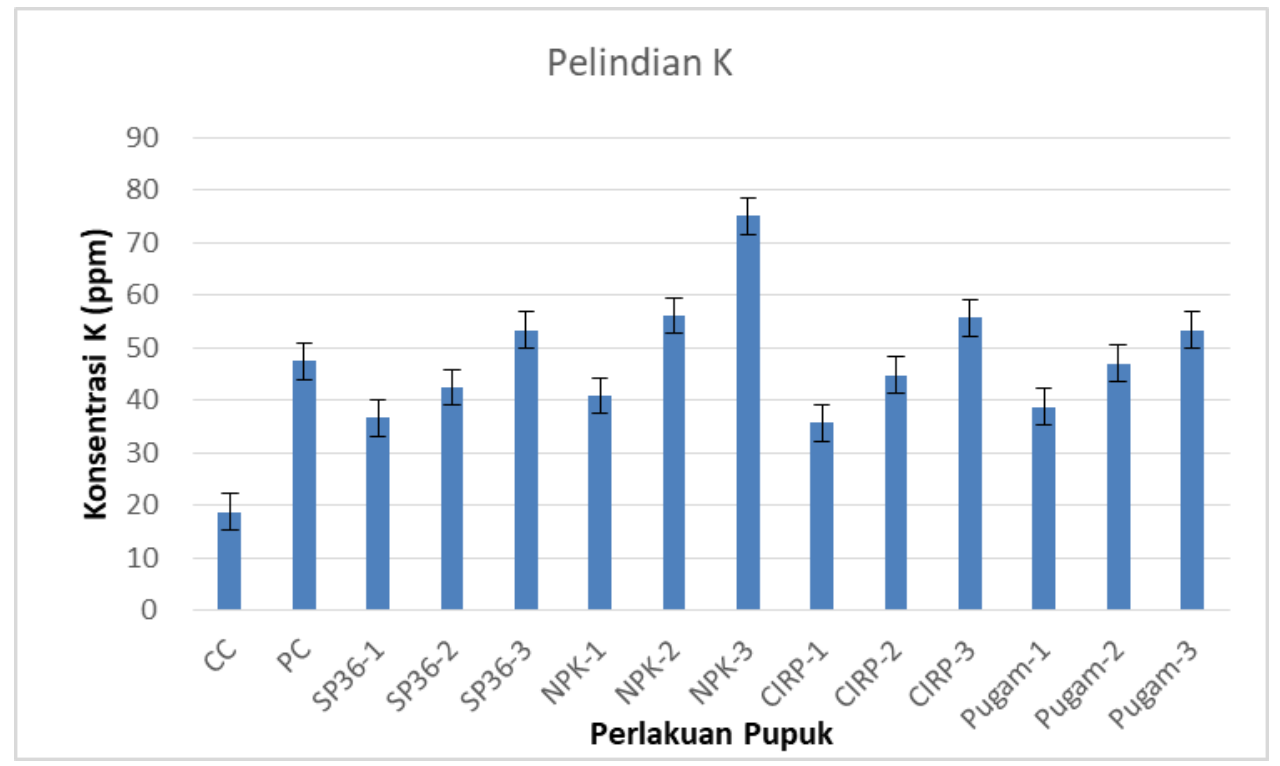

Gambar 7. Konsentrasi hara K pada air leachate pada inkubasi 28 hari.

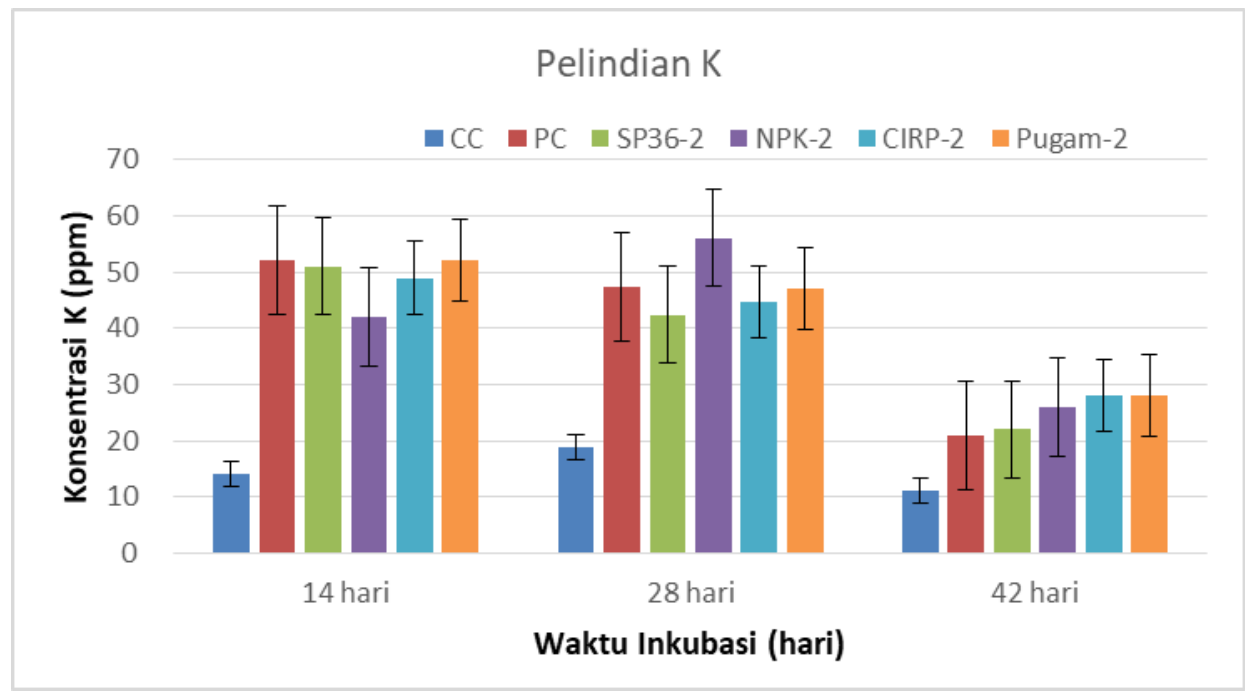

Gambar 8. Dinamika konsentrasi K pada air leachate pada inkubasi 14 hari, 28 hari dan 28 hari. 


\section{KESIMPULAN}

1. Pelindian $\mathrm{N}$ dalam bentuk $\mathrm{N}$-nitrat lebih tinggi dibandingkan dengan $\mathrm{N}$ amonium karena tanah gambut memiliki muatan negatif yang mampu menahan kation $\mathrm{NH}_{4}$.

2. Pelindian $\mathrm{N}$ lebih dominan disebabkan karena karena pengaruh dosis aplikasi $\mathrm{N}$, dimana makin tinggi dosis aplikasi, maka kehilangan $\mathrm{N}$ melalui pelindian makin besar.

3. Pelindian $\mathrm{P}$ menunjukkan perbedaan yang nyata dimana perlakuan pupuk CIRP dan Pugam terlindi lebih rendah dibandingkan dengan perlakuan pupuk NPK dan SP-36. Dosis aplikasi pupuk juga menunjukkan perbedaan yang nyata dimana makin tinggi dosis pupuk, maka kehilangan $\mathrm{P}$ melalui pelindian semakin besar.

4. Pelindian $P$ tidak hanya dipengaruhi oleh tingkat kelarutan $\mathrm{P}$ pupuk, tetapi juga dipengaruhi oleh keberadaan $\mathrm{Fe}$ dan $\mathrm{Al}$ yang berfungsi sebagai kation polivalen yang membentuk muatan positif tanah untuk tapak jerapan $P$.

5. Pelindian $\mathrm{K}$ tidak dipengaruhi oleh jenis pupuk yang diberikan, tetapi dipengaruhi oleh dosis aplikasi $\mathrm{K}$ dimana makin tinggi dosis $\mathrm{K}$, pelindian $\mathrm{K}$ makin besar.

\section{UCAPAN TERIMA KASIH}

Terima kasih diucapkan kepada Balai Penelitian Tanah dan PT. Polowijo Gosari yang telah mendanai penelitian ini. Terima kasih juga kepada staf Instalasi Rumah Kaca dan Staf Laboratorium Kimia Balai Penelitian Tanah yang telah membantu mulai dari persiapan, pelaksanaan penelitian dan analisis contoh air, sehingga tulisan ini bisa selesai. Semoga Tuhan memberkati dan membalas bantuan yang telah diberikan.

\section{DAFTAR PUSTAKA}

Agus F dan IGM Subiksa. 2008. Lahan Gambut: Potensi untuk pertanian dan aspek lingkungan. Balai Penelitian Tanah dan World Agroforestry Centre (ICRAFT) Bogor, Indonesia.

Chapman AS, Foster IDL, Lees JA, Hodgkinson RA. 2005. Sediment delivery from agricultural land to rivers via subsurface drainage. Hydrol. Proc. 19, 28752897.

Chardon WJ, Schoumans OF. 2007. Soil texture effects on the transport of phosphorus from agricultural land in river deltas of Northern Belgium, The Netherlands and North-West Germany. Soil Use and Manage. 23 (suppl. 1), 1624.

Forsman DM and C Kjaergaard. 2014. Phosphorus release from anaerobic peat soils during convective discharge - Effect of soil Fe:P molar ratio and preferential flow. Geoderma 225: 21-32. https://www.sciencedirect.com/scien ce/article/pii/S0016706114000524

Halim A. 1987. Pengaruh pencampuran tanah mineral dan basa dengan tanah gambut pedalaman Kalimantan Tengah dalam budidaya tanaman kedelai. Disertasi Fakultas Pascasarjana, IPB. Bogor.

Hartatik W, K Idris, S Sabiham, S Djuniwati, dan JS Adiningsih. 2004. Pengaruh pemberian fosfat alam dan SP-36 pada tanah gambut yang diberi bahan amelioran tanah mineral terhadap serapan $\mathrm{P}$ dan efisiensi pemupukan P. Prosiding Kongres Nasional VIII HITI. Universitas Andalas. Padang.

Heathwaite AL, Quinn PF, Hewett CJM. 2005. Modelling and managing critical source areas of diffuse pollution from agricultural land using flow connectivity simulation. J. Hydrology 304: 446-461. 
Killpack S C and Daryl Buchholz. 2018. Nitrogen in the Environment: Leaching. https://extension2.missouri.edu/wq2 $\underline{62}$.

Kononova MM. 1968. Transformation of organic matter and their relation to soil fertility. Sov. Soil. Sci. 8:10471056.

Mario MD. 2002. Peningkatan produktivitas dan stabilitas tanah gambut dengan pemberian tanah mineral yang diperkaya oleh bahan berkadar besi tinggi. Disertasi Program Pascasarjana, Institut Pertanian Bogor.

Rachim A. 1995. Penggunaan kation-kation polivalen dalam kaitannya dengan ketersediaan fosfat untuk meningkatkan produksi jagung pada tanah gambut. Disertasi. Program Pascasarjana, Institut Pertanian Bogor.

Riley WJ, I Ortiz-Monasterio and PA Matson. 2001. Nitrogen leaching and soil nitrate, nitrite, and ammonium levels under irrigated wheat in Northern Mexico. Nutrient Cycling in Agroecosystems 61: 223 236.

Ritung et al., 2015. Sumber Daya Lahan Pertanian Indonesia. Dalam Husen et al. (Eds). IAARD Press.

Russel E W. 1973. Soil Condition and Plant Growth 10th edition Longman-LBS, London.

Sabiham S, TB Prasetyo dan S Dohong. 1997. Phenolic acid in Indonesian peat. In Rieley and Page (Eds). Pp. 289-292. Biodiversity and Sustainability of Tropical Peat and Peatland. Samara Publishing Ltd. Cardigan. UK.

Salampak. 1999. Peningkatan produktivitas tanah gambut yang disawahkan dengan pemberian bahan amelioran tanah mineral berkadar besi tinggi. Disertasi Program Pascasarjana, Institut Pertanian Bogor.
Schoumans OF. 2015. Phosphorus leaching from soils: process description, risk assessment and mitigation. $\mathrm{PhD}$ Thesis Wageningen University.

Soil Survey Staff. 2010. Keys to Soil Taxonomy. Eleventh Edition, 2010. Natural Resources Conservation Service-United States Department of Agricultural, Washington DC.

Stevenson FJ. 1994. Humus Chemistry. Genesis, Composition, and Reactions. John Wiley and Sons. Inc. New York. 443 p.

Subiksa IGM, K Nugroho, Sholeh and IPG Widjaja Adhi. 1997. The effect of ameliorants on the chemical properties and productivity of peat soil. In: Rieley and Page (Eds). Pp:321-326. Biodiversity and Sustainability of Tropical Peatlands. Samara Publishing Limited, UK.

Subiksa IGM, Sulaeman, dan IPG WidjajaAdhi. 1998. Pembandingan pengaruh bahan amelioran untuk meningkatkan produktivitas lahan gambut. Dalam Prosiding Pertemuan Pembahasan dan Komunikasi Hasil Penelitian Tanah dan Agroklimat. Bogor, 10-12 Februari 1998.

Thomas SM, Ledgard SF, and Francis GS. 2005. Improving estimates of nitrate leaching for quantifying New Zealand's indirect nitrous oxide emissions. Nutrient Cycling in Agroecosystems, 73, 213-226.

Tillman RW and D R Scotter. 1991. Movement of Solute associated with Intermittent Soil Water Flow II . Nitrogen and Cation. Aust. J. Soil Res. 29: 185 - 196.

Wild A. 1981. Mass Flow and Diffusion in D.J. Grreenland and M.H.B. Hayes (eds). The Chemistry of Soil Processes. John Wiley \& Sons New York. 